\title{
Erosive coping after the 2011 floods in Kenya
}

\section{Denis Opiyo Opondo}

Department of Sociology and Anthropology,

Maseno University,

Private Bag, Maseno, Kenya

E-mail: Opiyod@Yahoo.Co.Uk

\begin{abstract}
Periodic river floods have devastating social and economic impacts on poor households in the low-lying coastal and western regions of Kenya. This paper focuses on how households in Bunyala District coped with the impacts of flooding, and particularly the December 2011 River Nzoia flood. The data for the study was collected through a survey of 400 households, three focus group discussions, four in-depth interviews and six key informant interviews. Of the surveyed household-heads, 393 (98.4\%) reported negative impacts of the flood on farming, livestock and/or property. Coping strategies at household level included temporary relocation and migration, reduced expenditure on household needs, engagement in extra income-generating activities, selling of property and reliance on support from public and private agencies. The findings reveal that many of the coping measures that people use are erosive, as they have negative long-term effects on household livelihood sustainability.
\end{abstract}

Keywords: loss and damage; adaptation; agriculture; climate change; coping; erosive coping; extreme weather event; floods; livelihoods; Kenya; Africa.

Reference to this paper should be made as follows: Opondo, D.O. (2013) 'Erosive coping after the 2011 floods in Kenya', Int. J. Global Warming, Vol. 5, No. 4, pp.452-466.

Biographical notes: Denis Opiyo Opondo is a $\mathrm{PhD}$ candidate at Maseno University where he teaches sociology. He is a Researcher and Consultant in Social Development. He was the Principal Investigator in the Kenyan Component of the 'Loss and Damage in Vulnerable Countries Initiative' that was coordinated by the United Nations University Institute for environment and Human Security (UNU-EHS), Bonn.

\section{Introduction}

\subsection{Background}

The increased risk of floods due to climate change and increased climate variability such as El Niño in poor developing countries has been recognised (IPCC, 2007; IGAD and ICPAC, 2007).

There have always been floods which have occasioned devastating consequences worldwide. The current scenario is aggravated by climate change and human activities. Moreover, there is growing awareness of the effect of climate change on the frequency of floods especially in developing countries. A number of studies conducted by the 
Intergovernmental Panel on Climate Change (IPCC) predict future increases in flooding due to escalating storm activity and overall rise in amounts of precipitation (IPCC, 2007). Climatic changes include rising temperatures and highly variable rainfall patterns, which result in increased frequency of extreme weather events such as floods and droughts. For instance, it has been reported that the last two decades have recorded six years with the warmest temperatures. Rainfall variability has been observed in sub-Saharan Africa (SSA) with decreases recorded in the Sahel region and increases in the East and Central African region. Consequently climate-related disasters such as floods and droughts have doubled in these regions within the last quarter century. Mozambique, Malawi, Kenya, Madagascar and Ethiopia are examples of SSA countries likely to experience unexpected adverse weather patterns (World Bank, 2009).

The climate change-human-induced activity nexus is a complex phenomenon difficult to disentangle since human activities destroy the mechanisms through which nature minimises the destructive effects of natural disasters such as floods. These have increased flood peaks and reduced flood-carrying capacity of rivers because of excessive siltation of riverbeds and river mouths with many adverse impacts. In Kenya, floods disrupt social life, destroy property and result in loss of lives (Ministry of Water and Irrigation, 2009). UNEP and Government of Kenya (2009) reported that fatalities due to floods constitute about $60 \%$ of disaster victims in Kenya. In addition, floods have devastating impacts on agricultural and industrial production, manufacturing, infrastructure, tourism and public health (Mogaka et al., 2006; Mango et al., 2007).

Recurrent and periodic floods affect low-lying parts of the country such as river valleys, swamps, lake shores and the coastal areas - particularly in Western and Nyanza Provinces and Tana River District in Coast Province ${ }^{1}$ (Otiende, 2009; Ministry of Water and Irrigation, 2009). Future rainfall projections for Kenya up to the year 2030 broadly indicate that there will be increases in annual rainfall, with highest amounts expected in western parts of Kenya around Mount Elgon, Elgeyo Escarpment and Cherangani Hills (the catchment of River Nzoia which drains through Budalangi District). If these projections are accurate, there are likely to be far-reaching effects on the intensity and frequency of floods in the region (Mango et al., 2007; Ministry of Water and Irrigation, 2009). As a result of increased frequency and intensity of floods, thousands of people living in the lowlands are forced to move to higher ground and adopt various coping measures to survive (Ministry of Water and Irrigation, 2009). While these coping measures may be successful in the short term, they often have severe implications for longer-term livelihood sustainability. Many of the measures people adopt allow them to survive the impact of floods but not to recover from it. The resulting 'loss and damage' and inadequacy of coping mechanisms occasioned by floods therefore pull people into an ever-more vicious cycle of poverty.

Loss and damage is a new concept in climate change research. According to the working definition used in this study, the concept refers to "the negative effects of climate variability and climate change that people have not been able to cope with or adapt to" [Warner et al., (2012) p.20]. This includes the inability to respond adequately to climate stresses (such as the costs of inaction) and the costs associated with existing coping and adaptive strategies (erosive coping strategies and mal-adaptation). These costs can be either monetary or non-monetary and vary across households and communities according to levels of vulnerability, resilience and poverty. 
It may sometimes be difficult to separate coping from adaption but the two are not synonymous.

Warner et al. (2012) define coping as "generally short-term actions to ward off immediate risk, rather than to adjust to continuous or permanent threats or changes." Whereas adaptation responses are long-term adjustments aimed at overcoming the destructive impacts disaster events. It has been defined by UNFCCC (2007) as processes through which societies make themselves better able to deal with uncertain future. Therefore, adaptation to climate change involves measures to reduce the negative consequences of climate change or exploiting new opportunities by making appropriate adjustments. In the context of loss and damage due to climate changes, the residents of Bunyala District have adopted coping strategies that are erosive in nature. Therefore, it is necessary to put in place measures to support them develop capacities to enable them withstand the impacts of frequent floods. This paper studies the coping strategies that households adopted to deal with the impacts of the December 2011 flood on River Nzoia in Bunyala District. It goes beyond conventional coping strategies research, by studying in more detail the longer-term sustainability of the measures and by assessing impacts beyond coping and adaptation, in other words - 'loss and damage'.

\subsection{Study area}

This study was conducted in Bunyala District of Western Province of Kenya. The district covers an area of about $185 \mathrm{~km}^{2}$, of which $112 \mathrm{~km}^{2}$ is arable land (Busia District Development Plan, 2009) and has a population of about 66,723 people comprising 31,718 males and 35,005 females, with an average household size of six people. These households have small farms of about 2.4 acres on which they live, grow crops and keep livestock (Kenya National Bureau of Statistics, 2010). Bunyala District receives mean annual rainfall of about $750-1,015 \mathrm{~mm}$ and has a flat topography through which River Nzoia meanders, often spilling floodwaters over its banks on to large areas of the flood plain (Busia District Development Plan, 2009; Onywere et al., 2011). There are many settlements near the dykes along the river in some locations and encroachment into flood plains for agriculture, livestock keeping and fishing.

There is an irrigation scheme for rice production - Bunyala Irrigation Scheme which is located in both Busia and Siaya counties and covers a total area of 1,734 acres. The section within Bunyala District is about 1,031 acres. The irrigation scheme is managed by the National Irrigation Board which provides water and inputs to contracted local farmers. These are available to all individuals who own or access land within the coverage of the rice scheme (Busia District Development Plan, 2009). The rice scheme is affected when flood waters destroy rice fields and the main canal is usually converted into a water channel. According to the Budalangi District Agriculture Officer, "the National Irrigation Board lost 3000 bags of stored rice during the December 2011 floods." 
Figure 1 Location of Budalangi District (see online version for colours)

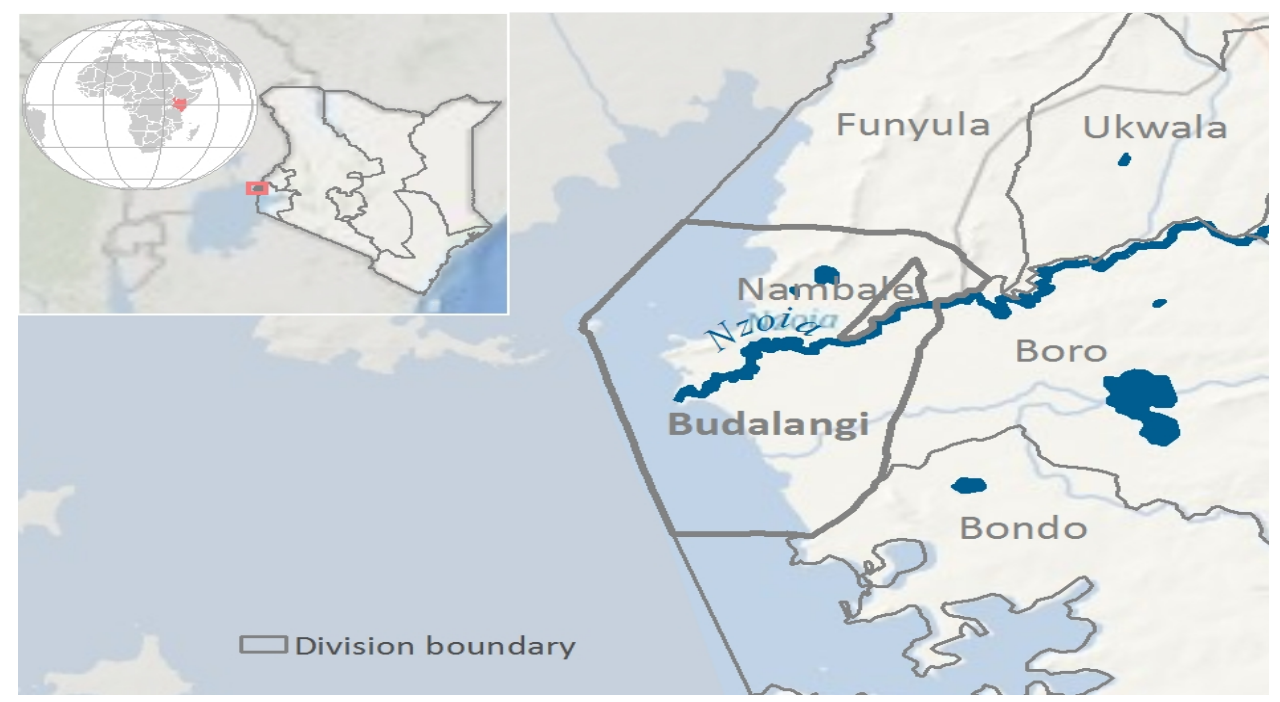

\subsection{Methodology}

The research findings presented in this paper were obtained from a case study on loss and damage associated with flooding conducted in Kenya. In June and July 2013, a household survey was conducted among a predetermined sample of 400 households spread across 17 sub-locations of Bunyala District. Stratification was used to select the sub-locations. The sample size for each sub-location was proportionately allocated based on the households within the jurisdiction of each village elder in that sub-location. Then households were randomly selected beginning at the most central part of each sub-location as guided by village elders. The first household was picked from this point and subsequently every fifth household was systematically selected in a clockwise direction until the required number of households was achieved per sub-location. Data was collected through an approach that combined a household questionnaire survey, three focus group discussions with a total of 25 women, men and youth, four in-depth interviews (with some respondents who participated in the household survey) and six key informant interviews with representatives of public and private organisations.

\section{Results and discussion}

\subsection{Socio-economic and demographic characteristics}

The people who live in Bunyala District are mainly Lunyala speakers and predominantly Christians. Most households (91\%) own small parcels of land averaging about 1.4 acres on which they live, farm and rear livestock. Their major socio-economic activities are crop cultivation, livestock keeping and non-farm activities including fishing, small-scale trade and manual labour. The mode of agricultural production is subsistence, with an 
overwhelming $94 \%$ of crop production reserved for household consumption and only about $6 \%$ available for sale.

The subsistence farmers earn about US $\$ 122$ annually from the sale of crops. Household incomes from farming and non-farm activities average about US\$1,001 per year. The farmers $(78 \%)$ reported reduced crop production due to floods that had inundated the land and washed away crops. This resulted in food scarcity and high food commodity prices (Otiende, 2009).

The study designed income categories for respondents to assess the relationship between income/wealth differentials and flood impacts. This information is presented in Table 1.

Table 1 Monthly income categories and perceptions on flood impacts

\begin{tabular}{lcccccc}
\hline \multicolumn{2}{l}{ Income categories } & & \multicolumn{4}{c}{ Perception of flood impacts } \\
\cline { 1 - 4 } \cline { 5 - 7 } KSH & USD & & No, not affected & Yes, but not severely & Yes, severely & Total \\
\hline $0-8000$ & $0-94$ & & $3(1 \%)$ & $75(25 \%)$ & $222(74 \%)$ & 300 \\
$8001-16000$ & $94-188$ & & $2(3 \%)$ & $21(28 \%)$ & $53(70 \%)$ & 76 \\
$>16,000$ & $>188$ & & $1(4 \%)$ & $6(26 \%)$ & $16(70 \%)$ & 23 \\
Total & & & $6(2 \%)$ & $102(26 \%)$ & $291(73 \%)$ & 399 \\
\hline
\end{tabular}

Table 1 shows that, most respondents (75\%) earn less than KSH 8,000 (US\$94) per month, while $19 \%$ earn between KSH 8,000-16,000 (US\$194-188) monthly and only $6 \%$ earn KSH 16,000 (US\$188) and above. The findings show that majority of the respondents are poor but a minority are well off. The proportion of respondents reporting that they were 'severely' affected by floods was high (73\%), and only minor differences were found between income groups. Even the few respondents who earn relatively higher incomes reported severe impacts. This position is supported by the views of one village elder: "But last year, our village was flooded for more than three weeks. I personally lost 61 bags of rice from my 4-acre farm. My crops were just washed away and I could not harvest anything. A bag of rice was worth about 3,700 shillings at the time of the flood so I lost 225,700 shillings (US\$2,640). Compared to others in my village, I am not a poor man. But the floods also affect wealthier people. We lose more. The poor can run away and save their lives. People like me suffer to save our property." ${ }^{33}$ In addition, one key informant observed that "most households did little to deal with the effects of floods. Poor peasant households lack money to buy land elsewhere. The only land they own is ancestral land in the flood zone. The elite from the community construct houses on their ancestral land but do not live in there and will renovate them in case of destruction from floods." 4

\subsection{Local perceptions and experience of floods}

In order to understand local perceptions and experiences of floods, respondents were asked to describe changes in the occurrence of floods over the last 20 years. In addition, they were also asked about flood impacts and coping strategies used to deal with the December 2011 flood. On perceptions of floods, about 301 respondents $(75 \%)$ reported significant changes in the occurrence of floods, while $77(19 \%)$ noted little change and only $11(3 \%)$ reported no change in flood events. The respondents reported that damaging floods occurred in the years 2002, 2003, 2008 and 2011. 
This was supported by findings from focus group discussions. Women participants in the second focus group discussion observed that the most recent and severe flood occurred in December 2011 and affected Magombe East, West and Central sub-locations. They also mentioned the September 2008 flood event (when River Nzoia burst its banks at Udunyi and flooded the northern dyke area) and the so-called 'El Niño' floods that occurred in most parts of Kenya between 1997 and 1998. In the same vein, in an in-depth interview, one village elder reported that

\begin{abstract}
"The December 2011 floods were the worst in the past 50 years and can be compared to the floods of 1960 and 1963 when there were no dykes yet. These were the most intense floods in the history of our area. The flood waters reached the village in the morning at around 10am. By evening $(6 \mathrm{pm})$ the whole area was like a lake and people were forced to relocate to safer ground. The frequency of floods within the dykes has increased to between 5 and 6 times a year. Nowadays, floods occur in June, August, September, October and December. In the past, floods occurred once a year in December and people dug drainage canals since water would not last for more than three days". 5
\end{abstract}

\title{
2.3 Floods impacts
}

The negative impacts of floods on households in Budalangi include loss of human life and destruction of property as well as disruption of social and economic activities. Respondents were asked about flood impacts on households and most (98\%) reported that the December 2011 flood had severe impacts on households. Only a very small number of respondents $(2 \%)$ were unaffected by that flood. The households most affected were those settled in the flood plain where they grew crops and raised livestock. The least affected households were settled on higher/raised land but cultivated in the flood plains. All the respondents in in-depth interviews and participants in focus group discussions agreed that, the loss of human life was the most severe impact of floods. For example, in the focus group discussion with men, "it was reported that a boat capsized on River Nzoia at Siginga and ten people died". 6

Figure 2 shows the impact of floods on different aspects of household economy, as reported by respondents. Figure 2 shows that floods severely affected crop production $(85 \%)$, food prices $(69 \%)$, housing/property $(44 \%)$, livestock $(41 \%)$ and trade $(13 \%)$. Other sectors affected were fishing and commercial trees. The impact on crop production was reported as either severe or moderate by $84 \%$ and $11 \%$ of households respectively. With respect to crop production, one respondent stated that:

\begin{abstract}
"All crops in the farms such as maize, sorghum, potatoes, beans and vegetables within and outside the dykes were washed away. There was nothing to harvest after the floods. Lack of food and poverty affected many poor households, particularly widows, orphans and the elderly. Flood waters killed cattle, sheep, goats and poultry. Grazing areas were submerged under water and livestock could not feed and so there was reduced milk supply."7
\end{abstract}

The impact of floods on livestock keeping was reported as either severe or moderate by $41 \%$ and $27 \%$ respondents. In regard to livestock keeping, participants in the focus group discussion with youth agreed that: "livestock - including cattle, goats, sheep and poultry - either died or were swept away. In addition, flooding destroyed grazing areas and led to increased incidence of livestock diseases. As a result some households sold their 
livestock at low prices to avoid losses and to obtain money to purchase food and other basic necessities."

Figure 2 Impact of floods on household economy (see online version for colours)

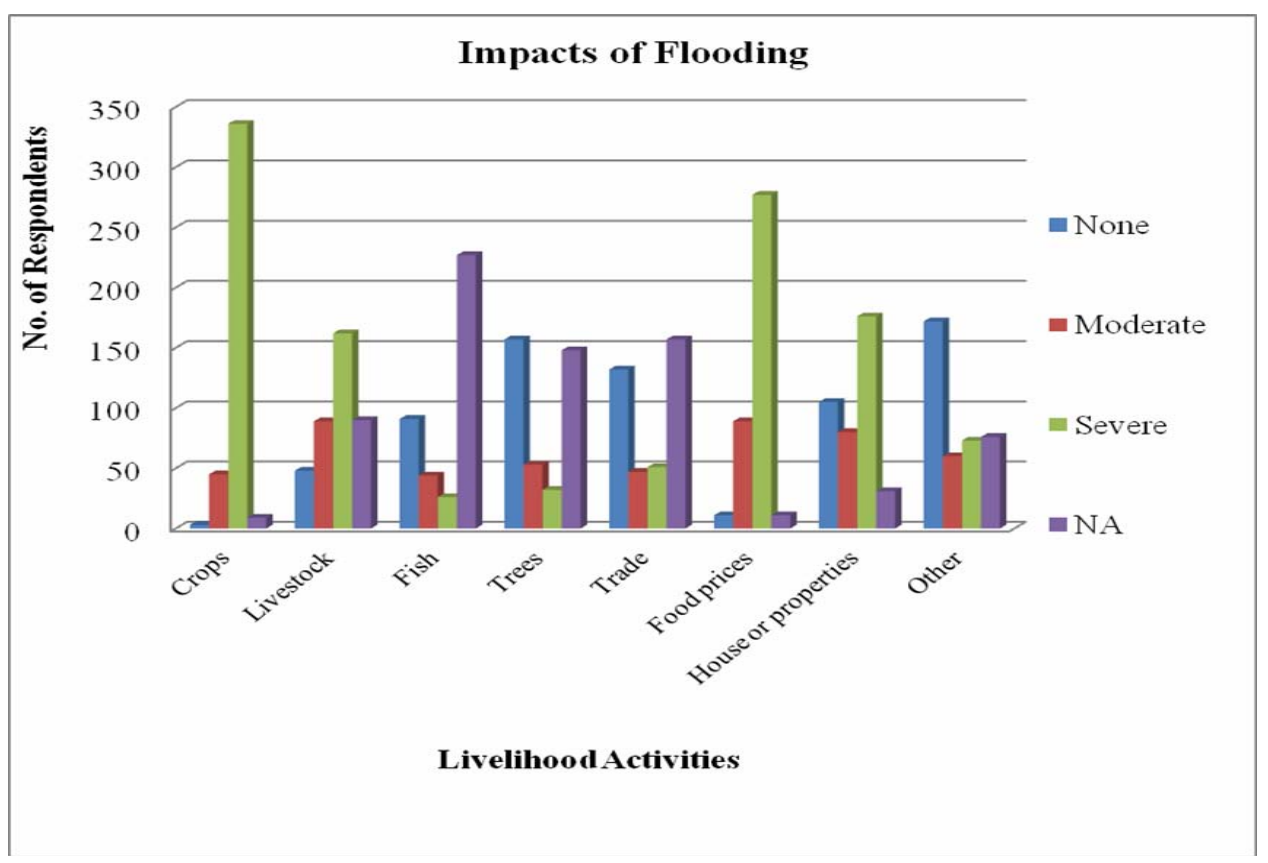

Figure 2 also shows that fishing, economic trees and trade activities were not severely affected by the floods. Flood impact on fishing and related activities was reported as either severe or moderate by $11 \%$ and $7 \%$ of the respondents. However, participants in the focus group discussion with men alluded to the fact that: fishing activities came to a standstill as fishing grounds and fish breeding areas were destroyed. This resulted in a low fish catch while "transportation of fish catch from Musoma and Mabinju beaches was hampered by bad roads.",

\subsection{Coping strategies}

The previous section discussed the impacts of flooding on households in Budalangi District. Almost all households (93\%) adopted at least one coping strategy to deal with those impacts. More often than not, several coping strategies were adopted. Coping with flood impacts involved efforts to get food, shelter, and clothing. The findings from the open and closed questions in the questionnaire, show that common coping strategies adopted by households included modification of food consumption patterns (82\%), help from organisations $(76 \%)$, reduced expenditure on household requirements $(71 \%)$, migration (59\%), engagement in extra income-generating activities (36\%), receiving help from other people (35\%) and sale of property (19\%). These coping strategies are shown in Table 2 and are discussed below. 
Table 2 Coping strategies adopted by households

\begin{tabular}{lcc}
\hline Coping strategies & Responses & Percent \\
\hline Modified food consumption & 328 & 82.2 \\
Support from organisations & 305 & 76.3 \\
Reduced expenses & 283 & 70.8 \\
Migrated & 237 & 59.3 \\
Earn extra income & 143 & 35.8 \\
Help from people & 141 & 35.2 \\
Sold property & 76 & 19 \\
\hline
\end{tabular}

\subsubsection{Modifying food consumption patterns}

Floods destroyed crops in farms and stored produce leading to food scarcity. Consequently, households which engage in small-scale subsistence farming may experience acute food shortage. Such households had to modify food consumption patterns such as reducing the number of meals and rationing the quantity of available food. The main modification of food consumption patterns are presented in Table 2 .

Table 3 shows that nearly two thirds $(63 \%)$ of respondents ate fewer meals per day. Some resorted to cheaper foods $(57 \%$, while reduced food portions was reported by $(32 \%)$ of measures of last resort used by respondents included adults eating less and fewer individuals eating at home. Food is a basic necessity and reducing food portions and number of meals per day highlights the desperation of households amid food scarcity. Thus, it is doubtful whether modification of eating patterns is a coping strategy or an indication of the failure of coping strategies.

Table 3 Food consumption patterns

\begin{tabular}{lcc}
\hline Food consumption & Responses & Percent \\
\hline Less meals per day & 250 & 62.5 \\
Cheaper food & 228 & 57 \\
Smaller portions & 126 & 31.5 \\
Adults eat less & 53 & 13.3 \\
Less people eat at home & 4 & 1.0 \\
\hline
\end{tabular}

\subsubsection{Support from organisations}

Flood events precipitated emergency rescue operations by public and private agencies. These were top-down interventions to save lives in crisis situations. In the aftermath of the December, 2011 flood, many residents received help from government and other organisations. Non-governmental organisations (NGOs) provided assistance to 275 $(69 \%)$ respondents, while $117(29 \%)$ respondents received help from government agencies. Only $30(8 \%)$ respondents received assistance from religious organisations. However, some respondents (24) \% did not get help from any organisation. The government agencies that provided assistance to residents included the ministries of water, health, fisheries, agriculture, provincial administration, defence and special programmes. Notable NGOs/CBOs that provided assistance included the Red Cross, 
Action Aid, USAid and Busia Community Development Organization (BUCODEV). In addition, international organisations such as United Nations Children's Emergency Fund (UNICEF) and World Food Programme (WFP) were mentioned in this category. The Catholic Church was identified as the main religious organisation that provided emergency assistance to flood victims.

Most households were evacuated to camps set up by public and private organisations, where they were provided with relief items such as clean water, food, medicine and shelter. Although more than $75 \%$ of the respondents received relief aid of one form or another, many complained that the assistance provided was inadequate. To this extent, Oonge Ochae, a local resident, stated:

\begin{abstract}
"I moved my family to the camp at Runyofu Primary School and stayed there for two months. I did not have money for food and depended on relief from the government and some NGOs. They provided tents and some relief food but this was not sufficient. As you can see, I have two sons and three daughters, one of whom is disabled. Imagine living with all of them in a tent! It was very stressful. I did nothing to deal with the floods because I did not have money and depended on relief aid. My dependence on others means I lack respect in the community. I am tired of relief aid from the government and NGOs. Being a recipient of aid all the time is not good. If I had the resources, I would move to a place where I can farm and do things to help other people. The government should consider giving us land in a place where we can live and be productive. Otherwise permanent dykes should be constructed to control the flow of water in the river." $" 10$
\end{abstract}

Similarly, a village elder observed that, "Aid or relief is not sustainable, for how long will we be given relief? What the people need is a permanent solution so that they can continue to live and feed their families."

\title{
2.4.3 Reduction of expenses
}

This was a coping strategy to reduce expenditure on household requirements. It entailed spending less money on important household needs such as food, education of children, healthcare, investment in productive activities, and maintenance of homes. When asked about the use of this coping strategy, about 283 households (71\%) reported reduced expenditure on household necessities. Reduced expenditure on food and maintenance of houses was reported by $66 \%$ and $28 \%$ households respectively. The aim was to conserve resources in order to survive during and after floods events.

\subsubsection{Temporary migration and relocation}

Another coping strategy adopted during floods was temporary migration and relocation. Some households temporarily migrated or relocated because of the December 2011 floods. The study found that of the 237 households $59 \%$ who used this coping mechanism, at least one member had migrated or relocated temporarily. But for $53 \%$ of the 237 respondents, all household members had migrated. Many households $60 \%$ migrated or relocated for short-term periods of less than six months, while $40 \%$ moved for longer periods of more than six months. The destination of migration was rural, $96 \%$ for most households and urban 3\% for a few households. Migration and temporary 
relocation often entailed movement to camps set up by the public agencies, NGOs and religious organisations, though some households moved to stay with relatives.

\subsubsection{Engagement in extra income-generating activities}

Some households participated in extra income-generating activities to buy food and pay for other household requirements in order to deal with the effects of floods. The households which attempted to engage in extra income-generating activities either intensified existing activities $24 \%$ or engaged in new activities $14 \%$. The main sources of extra income consisted of non-farm activities including small-scale trade, basketry, carpentry, masonry, sale of local alcoholic brews, farming, fishing, farm labour, bicycle repair, motor cycle and bicycle transport, brick making, water vending, sand harvesting and tailoring.

\subsubsection{Help from other people}

In the social set up of Bunyala, people depend on others for mutual assistance in times of crisis and need. Thus, about $35 \%$ of households reported receiving help from relatives, neighbours and friends in both cash and kind. Among the households who used this coping mechanism, $29 \%$ received help from relatives while only $8 \%$ obtained help from friends.

\subsubsection{Sale of property}

The sale of household property was a strategy used by some household heads to obtain money for the purchase of food and non-food items. This strategy was used by $19 \%$ of the households. Table 4 shows the proportion of households who sold different kinds of property.

Table 4 Sale of household property

\begin{tabular}{lcc}
\hline Property sold & Responses & Percent \\
\hline Livestock & 53 & 69.7 \\
Land & 22 & 28.9 \\
Transport & 3 & 3.9 \\
Luxury items & 3 & 3.9 \\
Productive assets & 2 & 2.6 \\
House & 1 & 1.3 \\
\hline
\end{tabular}

As shown in Table 4, livestock and land were the most commonly sold assets as reported by 53 and 22 households respectively. Only six households sold their bicycles and mobile phones. On sale of livestock, participants in the focus group discussion with young people all agreed that: "herds of between 10 and 20 animals were considered large. Some of the animals in such herds could be sold to obtain money to restock up on foodstuff such as maize, purchase materials for reconstruction of houses, and drugs to treat the remaining livestock suffering from waterborne diseases, and buy or lease farms elsewhere". ${ }^{12}$ 


\subsection{Erosive coping}

This study assessed the coping strategies adopted by households in response to the December 2011 flood in Bunyala District. The study has shown that many coping strategies have limitations and several are problematic, with erosive characteristics. Erosive coping is a series of actions undertaken by households to return to normal life after flood events but which have long-term negative effects on household economy and livelihood sustainability (van der Geest and Dietz, 2004). Therefore, when people are confronted with flood risks like in Bunyala, they make attempts to diversify livelihood sources but when these are inadequate, people must still cope with the resultant food and livelihood stress. Recurrent floods can exhaust the reserve of assets that people have built up over time, thus compromising their ability to cope effectively. As a result livelihood options diminish, with serious implications for their future livelihood security. Therefore, actions or coping strategies that seriously affect people's future livelihood security can be termed 'erosive' (van der Geest and Dietz, 2004). The erosive character of the coping strategies is illustrated in Table 5 .

Table 5 Erosive coping strategies

\begin{tabular}{|c|c|}
\hline Coping strategy & Costs \\
\hline Sale of property & $\begin{array}{l}\text { - Reduced household asset base } \\
\text { - Less land for farming hence less food and income from crop sales } \\
\text { - Sale of livestock reduces possibility of animal traction power for } \\
\text { farming, income and food (e.g., milk or eggs) }\end{array}$ \\
\hline $\begin{array}{l}\text { Extra income- } \\
\text { generating activity }\end{array}$ & $\begin{array}{l}\text { - Less time for crop production } \\
\text { - Hand-to-mouth existence, hence less chance of capital } \\
\text { accumulation } \\
\text { - Children withdrawn from school to help run small-scale } \\
\text { businesses or participate in non-farm work } \\
\text { - Irregular school attendance and poor educational attainment }\end{array}$ \\
\hline $\begin{array}{l}\text { Reduced expenditure on } \\
\text { household requirements }\end{array}$ & $\begin{array}{l}\text { Less food, hence no energy for farming and other productive } \\
\text { activities } \\
\text { - Less food means poor nutrition, hence poor health, malnutrition, } \\
\text { brain development affected leading to low educational attainment } \\
\text { and less money for education, children withdrawn from school } \\
\text { - Less money for health, leading to poor health and less money for } \\
\text { house maintenance - poor shelter, hence unsanitary conditions }\end{array}$ \\
\hline $\begin{array}{l}\text { Migration and } \\
\text { temporary relocation }\end{array}$ & $\begin{array}{l}\text { - Stay with relations, depends on goodwill } \\
\text { - Inadequate facilities in camps, no privacy } \\
\text { - Homes and property abandoned } \\
\text { - Loss of household property and need of money to rebuild } \\
\text { - Children and young people not supervised }\end{array}$ \\
\hline
\end{tabular}

Source: Synthesised from Opondo (2012)

The findings show that many coping strategies employed by households are potentially erosive. First, the sale of property reduces people's asset base and makes them more 
vulnerable in the face of recurrent floods. The sale of land is particularly detrimental to long-term livelihood sustainability. When people have less land available for crop production, then they are more likely to face food shortage even in the absence of floods or droughts. The other important property sold was livestock, mainly cattle. This not only affected the household asset base but also the opportunity to use animal traction power for farming and income from cultivating other people's farms. According to Mango et al. (2007) argue that floods destroy household assets as the effects force people to dispose of assets to cope in the short term. Second, the engagement of households in extra income-generating activities could be counterproductive, as it often meant less time available for their farming, livestock and fishing activities. In addition, venturing into other income-generating activities could mean withdrawing children from school to help with work such as petty trade. Children, particularly girls are an important source of labour in rural areas and may be forced to miss school, resulting in low or irregular school attendance or even early drop-out (Webster, 1984). This will reduce the opportunities for the affected children and households to improve their future life chances.

Third, the strategy of reducing expenditure on household requirements negatively affects present and future household circumstances. Less expenditure on food means having an unbalanced diet. Reduced food intake or consumption of less nutritious food means people lack physical strength to work on their farms or in other occupations. Less well-fed children perform poorly in school and have low educational attainment as malnutrition affects their brain development Webster (1984, p.122). Similarly, reduced expenditure on health and house maintenance increases the likelihood of ill health, poor shelter and unsanitary living conditions. Equally deleterious to household welfare and socio-economic status is reduced expenditure on productive investments. This limits the capacity to diversify or generate more resources and assets that could provide insurance against unexpected future tragedies such as floods.

Fourth, migration and temporary relocation mainly to camps or higher ground was adopted for the safety and security of family members, household goods and livestock in the aftermath of floods. As a result homesteads were abandoned and fell into disrepair. The camps to which households were evacuated were set up in schools, health facilities and churches, and often lacked basic sanitary facilities and privacy. In the congested environment of the camps, children and young people were usually unsupervised and some became truants, engaging in drug abuse and petty crime. For households who moved away to stay with relatives or friends, assistance was based on goodwill and the availability of resources, which could get exhausted and lead to strained relations over time. As a result, many people lost the social networks needed to draw upon to deal with future flood events.

The erosive coping strategies adopted are harmful to household livelihoods, health and socio-economic status and highlights the vulnerability of households in Bunyala District when faced with the disastrous flood impacts. In an in-depth interview, a youth respondent observed that, "the main problem with the effects of floods in Budalangi is lack of money and knowledge of what to do particularly because these floods occur so often, almost every two years. Therefore, some families have abandoned their homes and migrated to other places and local towns like Sio Port."13 


\subsection{Adaptation}

The adaptation of households to extreme weather events like floods can be assessed at various levels such as household, local community and institutional levels (this includes government agencies, NGOs and other civil society agencies). Findings from the focus groups discussions and in-depth interviews show that at the household and community levels, people undertake various adaptive options. These include hiring or purchase of alternative land in areas not affected by the floods, planting early maturing crops (such as egg beans, sweet potatoes, cow peas and vegetables), irrigation, planting water resistant crops and early planting immediately after the floods (to take advantage of the wet soil). In this regard, one out of five (19\%) respondents (subsistence farmers) reported increased crop productivity from planting early after floods or planting water-tolerant crops like yams. Another strategy used by respondents who own livestock was to graze on higher grounds or take animals to the homes of friends and relatives for safe custody. Adaptive fishing methods used included small size fishing nets, fishing in ponds and stagnant flood waters, and increased fishing in Lake Victoria. Other actions included voluntary community dyke monitoring to reduce breaches, avoidance of farming within the dykes, migration to areas that experience no flooding while leaving flood prone areas for farming, and participation in non-farm activities such as running small-scale businesses and trade in farm produce.

\subsection{Conclusions}

The study findings show that households in Budalangi are aware that climate change is happening today and recognise the increased frequency and intensity of floods in their area. Their perceptions have influenced the adoption of some coping measures to deal with the impacts of floods. Some of the coping strategies adopted devalue household assets with long-term negative effects. This study demonstrates that coping strategies can lead to unsustainable present and future livelihoods for residents of flood-prone areas. It contributes to the nascent body of literature on the new concept of loss and damage from climate change and attempts to shows that already there are climate stressors (floods) that go beyond people's capacity to cope and adapt. Many households interviewed on flood impacts in Budalangi District were forced to adopt coping strategies that were effective in the short-term, but erosive in the medium to long-term. Households had to deal with the economic disruption and social dislocation resulting from floods. In addition, they had to cope with the social and emotional stress of dealing with death, disease, loss of shelter, food shortage, loss and destruction of property.

The current situation and evidence from this study indicates that erosive coping measures require policy intervention to enable households to develop the capacity to utilise resources available locally to cope with flood impacts more sustainably. This is important since with limited resources and production options, poor households recover more slowly from the adverse impacts of floods and have insecure livelihoods (Mango et al., 2007). Households with diverse resources or the ability to access other livelihood options may be in a position to manage climate-related loss and damage. Those households without such opportunities for livelihood diversification incur increasing costs as they struggle to survive. 


\subsubsection{Policy recommendations}

In order to address the challenges due to flood impacts and the erosive coping strategies adopted by households, this paper makes a number of recommendations for planners and policy makers. First, it proposes an integrated watershed management policy for environmental conservation to reduce human activities that aggravate flood impacts in the River Nzoia basin. The policy should focus on land use afforestation, soil erosion control and water management systems (this should incorporate dams to regulate river flow and harvest flood water for agricultural, domestic and industrial use for increased food production and environmental sustainability). Second, there is need to enforce land use laws and regulations to discourage human encroachment into wetlands and flood plains (that act as buffers and filters of flood waters). This will go a long way in minimising human tragedies triggered by natural disasters such as floods. Third, an all-inclusive stakeholder participation process is necessary for planning and implementing long-term watershed management and flood mitigation interventions. Interventions such as construction of dams and dykes could benefit from the wealth of traditional knowledge accumulated over the years by the local communities. Finally, other interventions are required to help residents of Budalangi District to develop the capacity and skills to exploit the potential of livelihood activities not adversely affected by floods such as fishing, planting trees for timber and fruits and trade. These livelihood options can provide an entry point for reducing vulnerability and helping the residents of Budalangi District to overcome the devastating impacts of floods.

\section{References}

Busia District Development Plan (2009) Busia District Development Plan 2008 - 2012, Ministry of Planning National Development and Vision 2030, Nairobi.

Intergovernmental Authority on Development (IGAD) and Climate Prediction and Applications Centre (ICPAC) (2007) Climate Change and Human Development in Africa: Assessing the Risks and Vulnerability of Climate Change in Kenya, Malawi and Ethiopia, United Nations Development Programme, Nairobi.

Intergovernmental Panel on Climate Change (IPCC) (2007) Climate Change 2007: Impacts, Adaptation and Vulnerability, Summary for policy makers [online] http://www.ipcc.cg/SPM13apr07.pdf (accessed 20 January 2013).

Kenya National Bureau of Statistics (2010) 2009 Kenya Population and Housing Census: Volume II Population and Household Distribution by Socio-economic Characteristics, Nairobi.

Mango, N., Kirui, A.I. and Yitambe, A. (2007) 'Status of disaster risk management in Kenya', in Waswa, F., Otor, S., Olukoye, G. and Mugendi, D. (Eds.): Environment and Sustainable Development: A Guide for Higher Education in Kenya, Vol. II, School of Environmental Studies and Human Sciences, Kenyatta University, Nairobi, pp.158-178.

Ministry of Water and Irrigation (2009) Flood Mitigation Strategy, Nairobi.

Mogaka, H., Gichere, S., Davis, R. and Hirji, R. (2006) Climate Variability and Water Resources Degradation in Kenya: Improving Water Resources Development and Management, World Bank, Washington, DC.

Onywere, S.M., Getenga, Z.M., Mwakilala, S.S., Twesigye, C.K. and Nakiranda, J.K. (2011) 'Assessing the challenge of settlement in Budalangi and Yala swamp area in Western Kenya using landsat satellite imagery', The Open Environmental Engineering Journal, Vol. 4, pp.97-104. 
Opondo, O.D. (2012) Loss and Damage Associated with Adverse Livelihood Impacts of Flooding in Budalangi Division, Western Kenya, Loss and Damage in Vulnerability Countries Initiative, United Nations University Institute for Environment and Human Security (UNU-EHS), Bonn, Unpublished Report.

Otiende, B. (2009) 'The economic impacts of climate change in Kenya: riparian flood impacts and cost of adaptation' [online] weadapt.org/knowledge-base/files/758/4e25a4b8c8bf61C-kenyariparian-floods-case-study.pdf (accessed August 2013).

United Nations Environment Programme (UNEP) and Government of Kenya Regional Centre for mapping of Resources for Development and United States Geological Survey (2009) Kenya: Atlas of our Changing Environment, Nairobi.

United Nations Framework Convention on Climate Change (UNFCCC) (2007) Climate Change: Impacts, Vulnerabilities and Adaptation in Developing Countries, United Nations, Bonn.

van der Geest, K. and Dietz, T. (2004) 'A literature survey about risk and vulnerability in drylands, with a focus on the Sahel', in Dietz, A.JT. et al. (Eds.): The Impact of Climate Change on Dry Lands, Kluwer, Dordrecht.

Warner, K., van der Geest, K., Kreft, S., Huq, S., Harmeling, S., Koen, K. and de Sherbinin A. (2012) Evidence from the Frontlines of Climate Change: Loss and Damage to Communities Despite Coping and Adaptation, Loss and Damage in Vulnerable Countries Initiative, Policy Report, Report No. 9, United Nations University Institute for environment and Human Security (UNU-EHS), Bonn.

Webster, A. (1984) Introduction to Sociology of Development, 2nd ed., Macmillan, London.

World Bank (2009) Making Development Climate Resilient: A World Bank Strategy for Sub-Saharan Africa, Report number 46947, Washington, DC.

\section{Notes}

1 Due to the promulgation of a new constitution in 2010, Kenya has both a national government and 47 county governments. The administrative zones of provinces and districts have been absorbed into this framework.

2 Interview with the Budalangi District Agriculture Officer 27/7/2012.

3 In-depth interview with Benson Maina Okoth 25/8/12.

4 Interview with the Budalangi District Agriculture Officer 27/7/2012.

5 Ibid

6 Focus group discussion with men at Salvation Spirit Church of Israel East Africa Mowar on $1 / 8 / 12$.

7 Roseline Mbalaga (1962) Mabinju, 1/8/12.

8 Focus group discussion with youth at Salvation Spirit Church of Israel East Africa Mowar on $2 / 8 / 12$.

9 Focus group discussion with men at Salvation Spirit Church of Israel East Africa Mowar on $1 / 8 / 12$.

10 Interview with Oonge Ochao (1952) Mwangalalo village, Siginga sub-location.

11 Interview with Benson Maina Okoth, 25/8/12.

12 Focus group discussion with young people at the Salvation Spirit Church of Israel East Africa Mowar on 2/8/12.

13 Interview with Denis Masiga, Rugunga sub-location, 2/8/12. 